\title{
Tubular and Interstitial Expression of ICAM-1 as a Marker of Renal Injury in IgA Nephropathy
}

\author{
Pilar Arrizabalaga ${ }^{a}$ Manel Soléb Rosa Abellanac Xavier de las Cuevas ${ }^{d}$ \\ J osep Solere J ordi Pascualf ${ }^{f}$ Carlos Ascaso $^{c}$
}

Services of a Nephrology and bPathology, Hospital Clínic, Barcelona, cDepartment of Public Health, Institut d'Investigació Biomèdica August Pi i Sunyer, University of Barcelona, Barcelona, and Renal Units of dHospital of Terrassa, eHospital of Manresa, Barcelona and fClínica Girona, Girona, Spain

\section{Key Words}

IgA nephropathy $\cdot$ Renal intercellular adhesion molecule $1 \cdot$ Renal injury $\cdot$ Prognosis, IgA nephropathy

\begin{abstract}
Background: The upregulated renal expression of intercellular adhesion molecule 1 (ICAM-1) is associated with glomerular and interstitial infiltration of leukocytes. Aim: To test the hypothesis that renal expression of ICAM-1 may be predictive in the highly variable IgA nephropathy (IgAN). Methods: ICAM-1 (CD54) in tubular epithelium and interstitial leukocytes, macrophages (CD14), and T cells (CD3) were assessed using avidin-biotin-peroxidase in renal biopsy specimens from 45 patients with IgAN and from 29 patients with no glomerulonephritis. Results: In IgAN, tubular ICAM-1+ was seen in 25 of 45 (55\%) biopsy specimens, associated with glomerular hypercellularity, glomerulosclerosis involving less than $50 \%$ of the glomerular area, interstitial cellular infiltration, tubular atrophy, and proteinuria $(U=44, p=0.005)$. Interstitial ICAM-1+leukocytes were correlated with glomerulosclerosis involving less and more than $50 \%$ of the glomerular area, tubular atrophy, interstitial fibrosis, and serum creatinine concentration $(r=0.6343, p<0.001)$. In
\end{abstract}

\section{KARGER}

Fax + 41613061234

E-Mail karger@karger.ch

www. karger.com
(C) 2003 S. Karger AG, Basel

0250-8095/03/0233-0121\$19.50/0

Accessible online at:

www.karger.com/ajn patients with an increase of $50 \%$ in the serum creatinine concentration, interstitial ICAM-1+leukocytes and CD14+ and CD3+cells were significantly more numerous than in patients with a stable creatinine concentration. In patients with no glomerulonephritis, tubular ICAM-1+ was seen in 7 of 29 (24\%) biopsy specimens, inversely correlated with the number of normal glomeruli and associated with glomerulosclerosis covering more than $50 \%$ of the glomerular area, tubular atrophy, and creatinine. Conclusions: Tubular and interstitial expression of ICAM-1 can be a marker of tubulointerstitial disturbance in IgAN. Interstitial ICAM-1 may be an adverse predictor of disease progression.

Copyright $\odot 2003$ S. Karger AG, Basel

\section{Introduction}

Primary IgA nephropathy (IgAN) is the most common form of glomerulonephritis (GN) in the developed world, and it progresses to end-stage renal failure in about one third of the patients within 10 years [1]. Nephrotic-range proteinuria, renal function impairment, and hypertension at presentation are strong predictors of an adverse clinical outcome $[2,3]$. IgAN is characterized by predominantly

P. Arrizabalaga, MD

Servei de Nefrologia, Hospital Clínic

c/ Villarroel, 170

E-08036 Barcelona (Spain)

Tel. +3493 3598750, Fax +3493 359875, E-Mail parrizabala@senefro.org 
mesangial IgA deposition, often in conjunction with $\mathrm{C} 3$ and IgG and/or IgM, and appears with a highly variable degree of glomerular hypercellularity $[4,5]$ and capillaritis [6]. Tubulointerstitial damage [7] plays a major role in IgAN, in particular the infiltration of mononuclear leukocytes [8-11].

Renal entrapment and migration of leukocytes is mediated by interactions between adhesion molecules expressed on these cells and their ligands on renal cells. A major ligand in leukocyte trafficking is the intercellular adhesion molecule 1 (ICAM-1), a member of the immunoglobulin superfamily. ICAM-1 antigens are strongly expressed on monocytes and lymphocytes and are upregulated in vitro on epithelial and endothelial cells by several cytokines such as interleukin 1, tumor necrosis factor alpha, and interferon gamma [12]. In vivo, ICAM-1 expression is present on the normal renal vascular endothelium $[12,13]$. Induction of ICAM-1 expression has been reported on the mesangium in focal segmental glomerulosclerosis [14] and on parietal and tubular epithelium in proliferative GN [15-17], including IgAN [15, 18]. In this disease, the tubular expression of ICAM-1 is associated with infiltration of leukocytes [18], including the infiltration by $\mathrm{CD} 18+$ leukocytes that express the common beta chain of their counterligands $[19,20]$ leukocyte-function-associated antigen 1 (CD11a, CD18) and Mac-1 (CD11b, CD18), but its clinical significance remains uncertain. In order to examine the value of the renal expression of ICAM-1 as a marker of tubulointerstitial injury, we analyzed the relation between abnormal tubular and interstitial expression of ICAM-1 and renal impairment at the time of renal biopsy and the progression of the disease in a group of patients with IgAN in comparison with a group of patients with no glomerulonephritis (non-GN).

\section{Patients and Methods}

Forty-five patients with primary IgAN, 39 males and 6 females aged $39 \pm(\mathrm{SD}) 16$ years, and 29 patients with non-GN, 17 and 12 females aged $50 \pm$ (SD) 13 years, were studied. All patients showed serum creatinine levels below $3 \mathrm{mg} / \mathrm{dl}$. None of the patients with IgAN had clinical or biochemical evidence of Henoch-Schönlein purpura, liver disease, or systemic lupus erythematosus. The serum creatinine concentration was $1.6 \pm 0.7 \mathrm{mg} / \mathrm{dl}$, and proteinuria was $2 \pm$ $1.3 \mathrm{~g} / 24 \mathrm{~h}$. Hypertension, considered as a blood pressure above 130/ $85 \mathrm{~mm} \mathrm{Hg}$ at three determinations, was present in $23(51 \%)$ IgAN patients. The patients with non-GN had benign nephrosclerosis of presumed vascular origin (15), diabetes (5), amyloidosis (7), and acute tubular necrosis (2). Their serum creatinine level was $1.7 \pm$ $0.7 \mathrm{mg} / \mathrm{dl}$, and proteinuria was $2.8 \pm 1.6 \mathrm{~g} / 24 \mathrm{~h}$. Eighteen (62\%) patients presented hypertension. Most patients with hypertension received angiotensin-converting enzyme inhibitors in both groups. Serum creatinine, proteinuria, and blood pressure were recorded 2.4 \pm 2 years after renal biopsy in the patients with $\operatorname{IgAN}$ and $1.8 \pm 1.5$ years after renal biopsy in the patients with non-GN. An increase of at least $50 \%$ in serum creatinine or proteinuria or the presence of hypertension was considered as progression of the renal disease. Ten normal renal tissue specimens originally obtained from patients undergoing biopsies for diagnostic purposes in the same unit were used as controls.

\section{Tissues and Histological Assessment}

Diagnostic renal biopsy specimens taken by needle aspiration under sonographic control were processed for routine conventional light and immunofluorescence microscopy. In each specimen, the following histopathological glomerular features were evaluated in a blinded fashion: The number of glomeruli showing sclerosis involving less than $50 \%$ of the glomerular surface area and the number of glomeruli showing sclerosis involving more than $50 \%$ of the glomerular surface area. The number of glomeruli showing extracapillary proliferation, when at least two layers of nontubular cells occupied less than $20 \%$ of Bowman's space, was assessed in the biopsy specimens stained prominently for mesangial IgA. The number of normal glomeruli was assessed in specimens from non-GN patients. All biopsy specimens were evaluated for the degree of interstitial cellular infiltration, tubular atrophy, and interstitial fibrosis. The interstitial cellular infiltration was assessed as negative (-) when no cells were seen; + when cells were sparsely scattered; ++ when less than three infiltrate foci were detected; +++ when the number of foci was more than three, and ++++ when the whole tissue was infiltrated. The tubular atrophy and the interstitial fibrosis were assessed as negative (-) when absent; + when less than $25 \%$ of the tubuli or the interstitium was affected; ++ when the lesion was between 25 and $50 \%$, and +++ when the lesion affected more than $75 \%$ of tubuli or interstitium (table 1).

\section{Immunohistochemistry and Immunohistochemical Assessment}

Renal biopsy specimens selected on the basis of availability of material (at least 4 glomeruli) and ease of processing for immunohistochemistry were tested by means of the avidin-biotin-peroxidase method [20], using monoclonal antibodies against ICAM-1 (CD54, RM-3-A5) [21], which was applied after incubation with white of egg to block renal biotin, monocytes-macrophages (CD14, Cris-6) [22], and all T lymphocytes (CD3, Leu-4) (Becton Dickinson, Mountain View, Calif., USA). Tonsil tissue and slides from each specimen incubated with ascites fluid of myeloma NS1 or phosphate-buffered saline instead of monoclonal antibodies were used as controls. A Leitz microscope at magnification of $\times 400$ with an ocular grid $\left(0.07 \mathrm{~mm}^{2}\right)$ was used. CD54-positive tubular epithelial cells were scored as present or absent. CD54 staining on the proximal tubular epithelium was counted in 10-20 tubular cross-sections. The ratio of the area of CD54+ proximal tubular epithelium to total area of proximal tubule multiplied by a factor of 10 was calculated. Interstitial leukocytes identified by the above monoclonal antibodies were counted in 10-20 adjacent fields adjusted to avoid glomeruli and major vessels in an area of at least $0.2 \mathrm{~mm}^{2}$ on sequential renal sections. The number of positive leukocytes per square millimeter of interstitium was calculated. 
Table 1. Glomerular pathology and degrees of interstitial cellular infiltration, tubular atrophy, and interstitial fibrosis in IgAN and non-GN patients

\begin{tabular}{|c|c|c|c|c|c|c|c|c|c|c|c|c|c|c|}
\hline \multirow[t]{2}{*}{ Pathology } & \multicolumn{5}{|c|}{ Interstitial cellular infiltration ${ }^{\mathrm{a}}$} & \multicolumn{4}{|c|}{ Tubular atrophyb } & \multicolumn{4}{|c|}{ Interstitial fibrosis ${ }^{b}$} & \multirow[t]{2}{*}{ Total } \\
\hline & - & + & ++ & +++ & ++++ & - & + & ++ & +++ & - & + & ++ & +++ & \\
\hline \multicolumn{15}{|l|}{$\operatorname{Ig} A N^{\mathrm{c}}$} \\
\hline Minor & 5 & 3 & - & 1 & - & 4 & 5 & - & - & 2 & 5 & 2 & - & 9 \\
\hline Focal glomerulonephritis & 5 & 3 & 4 & 5 & 1 & 3 & 10 & 5 & - & - & 8 & 10 & - & 18 \\
\hline Diffuse glomerulonephritis & - & 2 & 5 & 2 & 1 & - & 3 & 7 & - & - & 2 & 7 & 1 & 10 \\
\hline Sclerosis & - & 2 & - & 5 & 1 & - & - & 4 & 4 & - & - & - & 8 & 8 \\
\hline Total & 10 & 10 & 9 & 13 & 3 & 7 & 18 & 16 & 4 & 2 & 15 & 19 & 9 & 45 \\
\hline
\end{tabular}

Non-GN

Nephrosclerosis

Diabetes

Amyloidosis

Acute tubular necrosis

Total

\begin{tabular}{rrrrrrrrrrrrrr}
- & 11 & 1 & 1 & 2 & - & 5 & 7 & 2 & - & 2 & 7 & 5 & 15 \\
- & 1 & 2 & 2 & - & - & - & 3 & 2 & - & - & 3 & 2 & 5 \\
4 & 1 & 1 & - & 1 & 2 & 1 & 4 & - & 1 & 1 & 1 & 4 & 7 \\
1 & 1 & - & - & - & - & 2 & - & - & - & - & 2 & - & 2 \\
\hline 5 & 14 & 4 & 3 & 3 & 2 & 8 & 15 & 4 & 1 & 3 & 14 & 11 & 29
\end{tabular}

a $\quad$ - = Interstitial cellular infiltration negative; $+=$ cells sparsely scattered; $++=$ less than three infiltrate foci detected; $+++=$ number of foci more than three; $++++=$ whole tissue infiltrated.

b $-=$ Tubular atrophy and interstitial fibrosis negative; $+=$ less than $25 \%$ of tubuli or interstitium affected; $++=$ lesions affected between 25 and $50 \%$ of tubuli or interstitium; +++ = lesions affected more than $75 \%$ of tubuli or interstitium.

c Minor glomerular abnormality when less than $20 \%$ of the glomeruli showed proliferative lesions; focal glomerulonephritis when $20-80 \%$ of the glomeruli showed proliferative lesions; diffuse proliferative glomerulonephritis when more than $80 \%$ of the glomeruli showed proliferative lesions; advanced sclerosis when more than $80 \%$ of the glomeruli showed predominant sclerotic lesions rather than proliferation.

\section{Statistics}

SPSS version 8 and Win 6.1.3 (SPSS, Chicago, Ill., USA) were used. The results were not normally distributed and were thus analyzed using the nonparametric Mann-Whitney $U$ test for two-group comparisons and the Kruskal-Wallis test for comparisons among several groups. Spearman's correlation coefficient was used to identify correlations of the quantitative value of the tubular expression of ICAM-1 and the interstitial ICAM-1+ leukocytes with the histological features, proteinuria, and creatinine serum levels at the time of renal biopsy. Differences were considered significant when $\mathrm{p}<0.05$.

\section{Results}

\section{Renal Expression of ICAM-1 in Normal Kidneys}

ICAM-1 (CD54) antigens were strongly expressed on peritubular and glomerular capillaries and endothelium of arterial vessels and veins. The tubular epithelium was negative. We observed occasional staining for CD54 and CD14, but no staining for CD3 within the interstitium in normal renal tissue.

ICAM-1 in IgA Nephropathy

\section{Renal Expression of ICAM-1 in IgAN}

A common pattern of ICAM-1 antigens was unchanged with respect to that observed in the normal kidney in IgAN without interstitial cellular infiltration and with interstitial cellular infiltration of grade + . In 25 of 45 (55\%) biopsy specimens from IgAN patients which showed interstitial cellular infiltration equal to or greater than ++ , ICAM-1 antigens were seen on the proximal tubule epithelium (fig. 1). The ratio of tubular ICAM-1 to total area of proximal tubule was $0.1 \pm(\mathrm{SD}) 0.18$, and it was associated with the score of interstitial cellular infiltration $(\mathrm{p}<0.001)$. The number of ICAM-1+ leukocytes was $234 \pm 307 / \mathrm{mm}^{2}$ of interstitium. Interstitial CD14+ leukocytes were $202 \pm 314 / \mathrm{mm}^{2}$, and CD3+ leukocytes were $466 \pm 415 / \mathrm{mm}^{2}$.

\section{Relationship between Expression of ICAM-1 and \\ Histological Features in IgAN}

ICAM-1+ tubules were detected in focal GN, diffuse GN, and advanced sclerosis (table 2). Tubular ICAM-1 was associated with glomerular sclerosis involving less than $50 \%$ of the glomerular surface area and with higher

Am J Nephrol 2003;23:121-128 


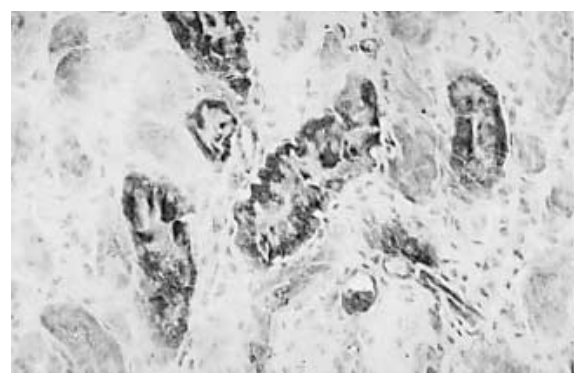

Fig. 1. ICAM-1 (CD54) antigens identified on the proximal tubule epithelium in a biopsy specimen with IgAN classified as diffuse proliferative glomerulonephritis. Avidinbiotin-peroxidase. $\times 250$.

Table 2. ICAM-1+ expression in tubules and interstitium in IgAN $($ mean $\pm \mathrm{SD})$

\begin{tabular}{llr}
\hline IgAN & \multicolumn{2}{l}{ ICAM-1+ } \\
\cline { 2 - 3 } & tubules $^{\mathrm{a}}$ & interstitium $^{\mathrm{b}}$ \\
\hline Minor & $0 \pm 0$ & $51.46 \pm 89.8$ \\
Focal glomerulonephritis & $0.05 \pm 0.01$ & $182.83 \pm 201.31$ \\
Diffuse glomerulonephritis & $0.24 \pm 0.3$ & $334.76 \pm 295.43$ \\
Sclerosis & $0.14 \pm 0.14$ & $437 \pm 456.12$ \\
\hline Kruskal-Wallis test & $10.916^{*}$ & 6.388 \\
\hline
\end{tabular}

a Ratio area of ICAM-1+ proximal tubule epithelium to total area of proximal tubules $\times 10$.

b Ratio number of interstitial ICAM-1+ leukocytes to area of interstitium.

$* \mathrm{p}<0.05$ for comparison among the four groups. degrees of tubular atrophy. Interstitial ICAM-1+ leukocytes were correlated with glomerular sclerosis involving less than $50 \%$ of the glomerular surface area, glomerular sclerosis involving more than $50 \%$ of the glomerular surface area, the degree of tubular atrophy, and the degree of interstitial fibrosis (table 3).

\section{Relationship between Expression of ICAM-1 and Clinical Data in IgAN}

At the time of renal biopsy, proteinuria was $2.7 \pm$ $1.5 \mathrm{~g} / 24 \mathrm{~h}$ in patients with tubular ICAM-1 versus $1.5 \pm$ $1.8 \mathrm{~g} / 24 \mathrm{~h}(\mathrm{U}=44, \mathrm{p}=0.005)$ in patients without (fig. 2). The interstitial ICAM-1+ leukocytes were $379.3 \pm 371 /$ $\mathrm{mm}^{2}$ in patients with hypertension versus $108 \pm 164.3 /$ $\mathrm{mm}^{2}(\mathrm{U}=52, \mathrm{p}<0.05)$ in patients with a normal blood pressure (fig. 3). A correlation was found between interstitial ICAM- $1+(\mathrm{r}=0.6343, \mathrm{p}<0.001$; table 4$)$ and serum creatinine concentration. At the end of the follow-up period, the patients who presented an increase of more than $50 \%$ in serum creatinine levels showed interstitial ICAM$1+$ leukocytes $516 \pm 360 / \mathrm{mm}^{2}$, CD14+ leukocytes 471.6 $\pm 174.7 / \mathrm{mm}^{2}$, and CD3+ leukocytes $836 \pm 295.5 / \mathrm{mm}^{2}$ versus interstitial ICAM-1+ leukocytes $66 \pm 87.8 / \mathrm{mm}^{2}$ $(\mathrm{U}=16, \mathrm{p}<0.005), \mathrm{CD} 14+$ leukocytes $246.2 \pm 216.7 /$ $\mathrm{mm}^{2}(\mathrm{U}=36, \mathrm{p}=0.01)$, and $\mathrm{CD} 3+$ leukocytes $420.8 \pm$ $366.6 / \mathrm{mm}^{2}(\mathrm{U}=22, \mathrm{p}=0.01)$ in the patients with stable serum creatinine concentrations (table 5).

\section{Renal Expression of ICAM-1 in Non-GN}

The distribution of ICAM-1 antigens was unchanged with respect to that observed in the IgAN patients, but ICAM-1 antigens on proximal tubular epithelium were

Table 3. Spearman's correlation coefficients between percentage of glomeruli with sclerosis involving less than $50 \%$ of the glomerular surface area, percentage of glomeruli with sclerosis involving more than $50 \%$ of the glomerular surface area, degree of tubular atrophy and degree of interstitial fibrosis and quantitative ICAM-1+ expression on tubules and interstitium in IgAN and non-GN patients

\begin{tabular}{|c|c|c|c|c|c|c|c|c|}
\hline \multirow[t]{3}{*}{ ICAM-1+ } & \multicolumn{4}{|l|}{ IgAN } & \multicolumn{4}{|c|}{ Non-GN } \\
\hline & \multicolumn{2}{|c|}{ tubules } & \multicolumn{2}{|c|}{ interstitium } & \multicolumn{2}{|c|}{ tubules } & \multicolumn{2}{|c|}{ interstitium } \\
\hline & $\mathrm{r}$ & $\mathrm{p}$ & $\mathrm{r}$ & $\mathrm{p}$ & $\mathrm{r}$ & $\mathrm{p}$ & $\mathrm{r}$ & $\mathrm{p}$ \\
\hline$\%$ glomeruli with sclerosis $<50 \%$ & 0.464 & 0.01 & 0.386 & $<0.05$ & -0.071 & NS & 0.201 & NS \\
\hline$\%$ glomeruli with sclerosis $>50 \%$ & 0.417 & NS & 0.549 & 0.01 & 0.558 & $<0.01$ & 0.147 & NS \\
\hline Tubular atrophy & 0.577 & 0.001 & 0.442 & $<0.05$ & 0.430 & $<0.05$ & -0.135 & NS \\
\hline Interstitial fibrosis & 0.372 & $<0.05$ & 0.405 & $<0.05$ & 0.304 & NS & -0.169 & NS \\
\hline
\end{tabular}


2

Fig. 2. Median and range, maximum and minimum, of proteinuria in patients with IgAN showing negative and positive ICAM1-staining tubular epithelium. Mann-Whitney $U$ test $=44(p=0.005)$.

Fig. 3. Median and range, maximum and minimum, of the number of infiltrating ICAM-1+ leukocytes $/ \mathrm{mm}^{2}$ interstitium in patients with IgAN showing a normal blood pressure and hypertension at the time of renal biopsy. Mann-Whitney U test $=52(\mathrm{p}<$ 0.05).
3

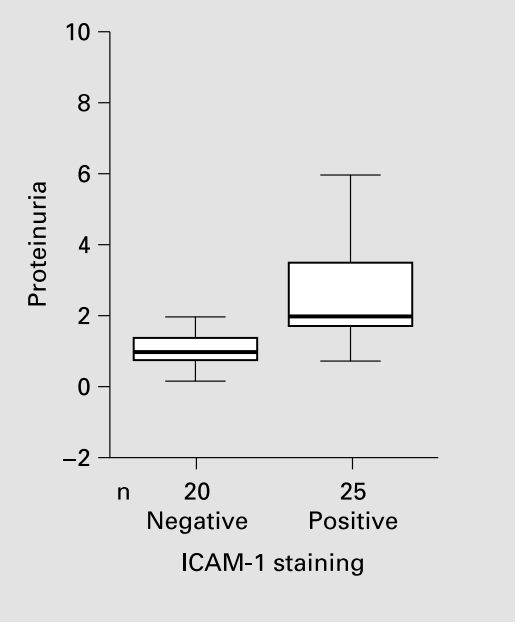

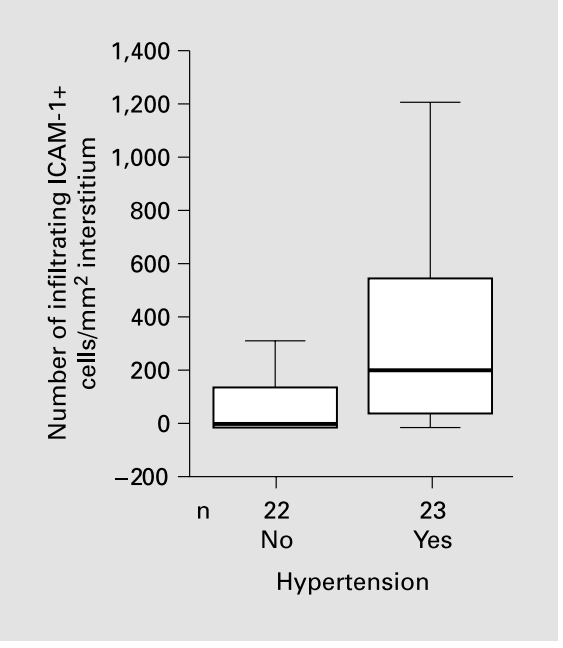

Table 4. Spearman's correlation coefficients between clinical data at the time of renal biopsy and quantitative ICAM$1+$ expression on tubules and interstitium and significant Mann-Whitney $U$ test results of the follow-up clinical data according to ICAM-1+ expression on tubules and interstitium in IgAN and non-GN patients

\begin{tabular}{|c|c|c|c|c|c|c|c|c|}
\hline \multirow[t]{3}{*}{ ICAM-1+ } & \multicolumn{4}{|l|}{ IgAN } & \multicolumn{4}{|c|}{ Non-GN } \\
\hline & \multicolumn{2}{|l|}{ tubules } & \multicolumn{2}{|c|}{ interstitium } & \multicolumn{2}{|l|}{ tubules } & \multicolumn{2}{|c|}{ interstitium } \\
\hline & $\mathrm{r}$ & $\mathrm{p}$ & $\mathrm{r}$ & $\mathrm{p}$ & $\mathrm{r}$ & $\mathrm{p}$ & $\mathrm{r}$ & $\mathrm{p}$ \\
\hline \multicolumn{9}{|l|}{ Renal biopsy } \\
\hline Proteinuria & 0.4059 & $<0.05$ & 0.2322 & NS & 0.063 & NS & 0.156 & NS \\
\hline \multirow[t]{2}{*}{ Serum creatinine } & 0.282 & NS & 0.6343 & $<0.001$ & 0.4356 & $<0.05$ & -0.203 & NS \\
\hline & $\mathrm{U}$ & $\mathrm{p}$ & $\mathrm{U}$ & $\mathrm{p}$ & $\mathrm{U}$ & $\mathrm{p}$ & $\mathrm{U}$ & $\mathrm{p}$ \\
\hline \multicolumn{9}{|l|}{ Follow-up } \\
\hline Proteinuria & 19 & NS & 13 & NS & 48 & NS & 8 & NS \\
\hline Serum creatinine & 41 & NS & 16 & $<0.005$ & 42 & NS & 12 & NS \\
\hline Hypertension & 48 & NS & 22 & $<0.05$ & 68 & NS & 42 & NS \\
\hline
\end{tabular}

detected only in 7 of 29 (24\%) biopsy specimens with interstitial cellular infiltration. The ratio of tubular ICAM-1 to total area of proximal tubule was $0.02 \pm 0.04$ $(\mathrm{U}=344, \mathrm{p}<0.05$, vs. IgAN). In contrast to IgAN, no association between tubular ICAM-1 and the score of interstitial cellular infiltration was observed. ICAM-1+ leukocytes were $191 \pm 113 / \mathrm{mm}^{2}$ interstitium $(\mathrm{U}=323$, n.s., vs. IgAN). Interstitial CD14+ leukocytes were $83.5 \pm$ $40.5 / \mathrm{mm}^{2}$ interstitium, and CD3+ leukocytes were 221.7 $\pm 172.4 / \mathrm{mm}^{2}$ interstitium.

\section{Relationship between Expression of ICAM-1 and Histological Features in Non-GN}

Tubular ICAM-1 was inversely correlated with the percentage of normal glomeruli $(r=-0.374, p<0.05)$ and associated with glomerular sclerosis involving more than $50 \%$ of the glomerular area and tubular atrophy (table 3 ).

\section{Relationship between Expression of ICAM-1 and Clinical Data in Non-GN}

At the time of renal biopsy, tubular ICAM-1 was correlated $(r=0.4356, p<0.05)$ with the serum creatinine level. No other association between either tubular or intersti- 
Table 5. Spearman's correlation coefficients between clinical data at the time of renal biopsy and significant MannWhitney U test results of the follow-up clinical data according to interstitial CD14+ and CD3+ in IgAN and non-GN patients

\begin{tabular}{|c|c|c|c|c|c|c|c|c|}
\hline & \multicolumn{4}{|l|}{$\mathrm{IgAN}$} & \multicolumn{4}{|c|}{ Non-GN } \\
\hline & \multicolumn{2}{|c|}{ CD14+ } & \multicolumn{2}{|l|}{$\mathrm{CD} 3+$} & \multicolumn{2}{|c|}{ CD14+ } & \multicolumn{2}{|l|}{ CD3+ } \\
\hline & $\mathrm{r}$ & $\mathrm{p}$ & $\mathrm{r}$ & $\mathrm{p}$ & $\mathrm{r}$ & $\mathrm{p}$ & $\mathrm{r}$ & $\mathrm{p}$ \\
\hline \multicolumn{9}{|l|}{ Renal biopsy } \\
\hline Proteinuria & 0.131 & NS & 0.132 & NS & 0.198 & NS & 0.091 & NS \\
\hline \multirow[t]{2}{*}{ Serum creatinine } & 0.441 & $<0.05$ & 0.208 & NS & 0.053 & NS & 0.085 & NS \\
\hline & $\mathrm{U}$ & $\mathrm{p}$ & $\mathrm{U}$ & $\mathrm{p}$ & $\mathrm{U}$ & $\mathrm{p}$ & $\mathrm{U}$ & $\mathrm{p}$ \\
\hline \multicolumn{9}{|l|}{ Follow-up } \\
\hline Proteinuria & 51 & NS & 35 & NS & 8 & NS & 3 & NS \\
\hline Serum creatinine & 36 & 0.01 & 22 & 0.01 & 2 & NS & 6 & NS \\
\hline Hypertension & 46 & 0.01 & 31 & $<0.05$ & 19 & NS & 10 & NS \\
\hline
\end{tabular}

tial staining for ICAM-1 (table 4), interstitial staining for CD14 or CD3 (table 5), and clinical data was found in non-GN.

\section{Discussion}

The vascular renal expression of ICAM-1 is unchanged in mild histological forms of IgAN with respect to that observed in the normal kidney. In severe forms of IgAN, there is an increase in glomerular staining for ICAM-1 [18], due either to infiltrating mononuclear leukocytes or to upregulated expression on endothelial $[23,24]$ and mesangial cells $[23,25]$. In addition, the expression of ICAM-1 is induced on the proximal tubule epithelium associated with glomerular [18] and interstitial cellular infiltration seen by light microscopy [13] and characterized by monoclonal antibodies directed to leukocytes [20, 26]. The serum ICAM-1 levels in histologically severe forms [27] and in both exacerbating clinical episodes and during quiescence $[26,28]$ are similar to those in healthy controls. Thus, the abnormal expression of ICAM-1 on the tubular epithelium appears to be a specific local phenomenon rather than a reflection of the serum level, but its significance is uncertain. This study analyzed the relation between the abnormal tubular expression of ICAM-1 and the interstitial leukocyte expression of ICAM-1 with the renal impairment at the time of renal biopsy and at the end of the follow-up period in a group of patients with
IgAN in comparison with a group of patients with nonGN.

Here we report data on a large group of patients with IgAN [15] and patients with non-GN as controls. We provide histological and clinical information $[15,18]$ defining the disease that extends that of earlier reports. The distribution of ICAM-1 antigens on vascular endothelium and interstitial leukocytes was similar in IgAN and in non-GN, but the levels of tubular ICAM-1 were significantly higher in IgAN. We found a significant association between the abnormal tubular expression of ICAM-1 and proteinuria in IgAN, whereas no association was noted in non-GN which suggests that the expression of ICAM-1 antigens on the tubular epithelial cells may be a result of the renal damage in IgAN. Thus, tubular ICAM-1 expression may be a marker of tubular injury in IgAN.

Glomerular high-grade proteinuria itself may cause tubular epithelial cell injury through several mechanisms [29] in experimental models of GN. Moreover, the association between the glomerular hypercellularity and the tubular expression of ICAM-1 observed in IgAN and the association between normal glomeruli and the lack of tubular stain for ICAM-1 observed in non-GN suggest that glomerular proliferation plays a role in the tubular expression of ICAM-1. Thus, the glomerular infiltration of macrophages [30,31] showing tumor necrosis factor alpha mRNA signals in histological studies of $\operatorname{IgAN}[32$, 33] supports that glomerular inflammatory cytokines, such as tumor necrosis factor alpha and interleukin 1, 
may reach the tubulointerstitium via blood, urine, or diffusion through extravascular tissue which is a stimulus for the induction of ICAM-1 on the tubular epithelium in this disease.

This study distinguished between glomerulosclerosis involving more than $50 \%$ of the glomerular surface area and glomerulosclerosis involving less than $50 \%$ of the glomerular surface area. An association between the abnormal tubular expression of ICAM-1 and the percentage of glomeruli showing sclerosis involving less than 50\% of glomerular surface area in IgAN was found which is in accordance with the adverse predictor factor of segmental hyalinosis and sclerosis in IgAN [34], even in patients with a normal renal function at the time of presentation [35]. Thus, the tubular staining for ICAM-1 at the time of diagnosis provides reliable information on the progression of this disease.

The association between ICAM-1 on proximal tubule epithelium and the severity score of interstitial infiltrating leukocytes in IgAN $[20,26]$, and not in non-GN as in our report, suggests that the tubular expression of ICAM-1 may be induced by interstitial cytokines and is not simply a by-product of extensive infiltration. In support of this hypothesis, $\mathrm{T}$ cells cloned from renal cellular infiltrates in experimental nephritis demonstrate specific autoreactivity against renal tissue and induce ICAM-1 on cultured tubular epithelial cells, the induction being blocked by a monoclonal antibody directed to interferon gamma [36]. Functional studies in different animal models of GN have demonstrated that cytokine-activated tubular epithelial cells can act as antigen-presenting cells and revealed an improvement in both clinical and histological manifestations of renal disease following the inhibition of ICAM-1 antigens [16, 37]. Alternatively, the correlation between the tubular expression of ICAM-1 and the tubular atrophy observed in IgAN and in non-GN suggests that the proximal tubular epithelium expressing ICAM-1 antigens could reflect both the participation of the tubular epithelial cells in local cell-mediated immune interactions and the tubular injury.

The correlation between the number of interstitial ICAM-1+ leukocytes and the histological features, such as glomerular sclerosis, tubular atrophy, and interstitial fibrosis, and the clinical features, such as the presence of hypertension, and the correlation with serum creatinine at the time of renal biopsy are in accordance with the role of the interstitial $\mathrm{T}$ lymphocytes and macrophages [38, 39] in tubulointerstitial injury in IgAN. In contrast to a more heterogeneous histological report including less than $10 \%$ of biopsy specimens with nonglomerular disease
[40], we did not find these associations in non-GN which indicates that the interstitial cell immunity could play a role in the renal impairment in IgAN, as has been demonstrated in experimental GN $[29,41]$.

The sum of CD14+ cells and CD3+ cells far exceeded the number of CD54+ cells. The number of CD54+ cells was little higher than the number of CD14+ cells. Moreover, the interstitial CD14 cellularity was correlated with the serum creatinine level at the time of renal biopsy. These observations indicate that the main ICAM-1+ cells infiltrating the interstitium are macrophages and that few of the CD3+ cells are activated [42]. Thus, the interstitial staining for ICAM-1 may be a marker of the participation of the cell immunity in tubulointerstitial injury in IgAN.

In conclusion, the tubular and the interstitial expression of ICAM-1 may be a valuable marker of tubulointerstitial disturbance in IgAN, for the following reasons: (1) the association between the abnormal tubular expression of ICAM-1 and proteinuria; (2) the association between the interstitial ICAM-1+ leukocytes and renal failure at presentation, and (3) the deterioration observed in IgAN. In spite of the association between ICAM-1+ tubules and the adverse factors of segmental hyalinosis and sclerosis in IgAN, interstitial ICAM-1 rather than tubular ICAM-1 could be used as a predictor of progressive deterioration in this disease.

\section{Acknowledgments}

The authors thank Dr. R. Vilella and P. Engel for generous gifts of CD54 and CD14 monoclonal antibodies and N. Babot for excellent immunohistochemistry. This study was supported by the Fondo de Investigación de la Seguridad Social (N 99/0187). 


\section{References}

1 D'Amico G: The commonest glomerulonephritis in the world: IgA nephropathy. Q J Med 1987;64:709-727.

2 Ibels LS, Gyori AZ, Caterson RJ, Pollock CA, Mahony JF, Waugh DA, Roger SD, Coulshed S: Primary IgA nephropathy: Natural history and factors of importance in the progression of renal impairment. Kidney Int 1997;52(suppl 61):67-70.

3 Ohno I, Hosoya T, Gomi H, Ichida K, Okabe $\mathrm{H}$, Hikita M: Serum uric acid and renal prognosis in patients with IgA nephropathy. Nephron 2001;87:333-339.

4 Habib R, Niaudet P, Levy M: Schönlein-Henoch nephritis and IgA nephropathy; in Tisher CC, Brenner BM (eds): Renal Pathology. Philadelphia, Lippincott-Raven, 1994, pp 472-523.

5 Haas M: Histologic subclassification of IgA nephropathy: A clinicopathologic study of 244 cases. Am J Kidney Dis 1997;29:829-842.

6 Ferrario F, Napodano P, Rastaldi MP, D'Amico G: Capillaritis in IgA nephropathy; in Clarkson AR, Woodroffe AJ (eds): IgA Nephropathy. Contrib Nephrol. Basel, Karger, 1995, vol 111 , pp 8-12.

7 D'Amico G, Ferrario F, Rastaldi MP: Tubulointerstitial damage in glomerular diseases: Its role in the progression of renal damage. Am J Kidney Dis 1995;26:124-132.

8 Sabadini E, Castiglione A, Colasanti G, Ferrario F, Civardi R, Fellin G, D'Amico G: Characterization of interstitial infiltrating cells in Berger's disease. Am J Kidney Dis 1988;12: 307-315.

9 Alexopoulos E, Seron D, Hartley RB, Nolasco F, Cameron JS: The role of interstitial infiltrates in IgA nephropathy: A study with monoclonal antibodies. Nephrol Dial Transplant 1989;4:187-195.

10 Falk MC, Ng G, Zhang GY, Roy P, Bannister KM, Thomas AC, Clarkson AR, Woodroffe AJ, Knight JF: Infiltration of the kidney by $\alpha \beta$ and $\gamma \delta$ T cells: Effect on progression in $\operatorname{IgA}$ nephropathy. Kidney Int 1995;47:177-185.

11 Ootaka T, Saito T, Yusa A, Munaketa T, Soma $\mathrm{J}$, Abe K: Contribution of cellular infiltration to the progression of IgA nephropathy: A longitudinal immunocytochemical study on repeated biopsy specimens. Nephrology 1995; 1: 135-142.

12 Pober JS, Cotran RS: Immunologic interactions of T lymphocytes with vascular endothelium; in Dixon FJ (ed): Advances in Immunology. New York, Academic Press, 1991, pp 261302

13 Müller GA, Markovic-Lipovski J, Müller CA: Intercellular adhesion molecule-1 expression in human kidneys with glomerulonephritis. Clin Nephrol 1991;36:203-208.

14 Canton DA, Fuiano G, Sepe V, Caglioti A, Ferrone $\mathrm{S}$ : Mesangial expression of intercellular adhesion molecule-1 in primary glomerulosclerosis. Kidney Int 1992;41:951-955.
15 Brujin JA, Dinklo JC: Distinct patterns of expression of ICAM-1, VCAM-1 and ELAM-1 in renal disease. Lab Invest 1993;69:329-335.

16 Adler S, Brady HR: Cell adhesion molecules and the glomerulopathies. Am J Med 1999; 107:371-386.

17 Arrizabalaga P, Sans A, Torras A, Darnell A, Revert L: Monoclonal antibody analysis of crescentic membranous glomerulonephropathy. Am J Nephrol 1998; 18:77-82.

18 Tomino Y, Ohmuro H, Kuramoto T, Shirato I, Eguchi K, Sakai H, Okumura K, Koide H: Expression of intercellular adhesion molecule1 and infiltration of lymphocytes in glomeruli of patients with IgA nephropathy. Nephron 1994;67:302-307.

19 Ootaka T, Saito T, Soma J, Yusa A, Abe K: Intercellular adhesion molecule-1/leukocyte function associated antigen-1-mediated and complement receptor type-4-mediated infiltration and activation of glomerular immune cells in immunoglobulin A nephropathy. Am J Kidney Dis 1996;28:40-46.

20 Arrizabalaga P, Solé M, Ascaso C, Quintó Ll: Intercellular adhesion molecule-1 mediated interactions and leucocyte infiltration in IgA nephropathy. Nephrol Dial Transplant 1997;12: 2258-2262.

21 Engel P, Serra C, Acevedo G, Vilella R, Gallart $\mathrm{T}$ : Involvement of CD18 and CD54 in the mixed lymphocyte reaction to leukemic CD5+ B lymphocytes. Immunology 1992;11:21-31.

22 Bernstein ID, Self S: Joint report of the myeloid section of the 2nd International Workshop on Human Leucocyte Differentiation Antigens; in Reinherz EL, Haynes BF, Nadler LM, Bernstein ID (eds): Leucocyte Typing II. New York, Springer, 1986, pp 1-25.

23 Dal Canton A: Adhesion molecules in renal disease. Kidney Int 1995;48:1687-1696.

24 Ogawa T, Yorioka N, Ito T, Ogata S, Kumagai J, Kawanishi H, Yamakido M: Precise ultrastructural localization of endothelial leucocyte adhesion molecule-1, vascular cell adhesion molecule-1, and intercellular adhesion molecule-1 in patients with IgA nephropathy. Nephron 1997;75:54-64.

25 Gauer S, Yao J, Schoecklmann HO, Sterzel B: Adhesion molecules in the glomerular mesangium. Kidney Int 1997;51:1447-1453.

26 Lhotta A, Schlögl A, Kronenberg F, Joannidis M, König P: Soluble intercellular molecule-1 (ICAM-1) in serum and urine: Correlation with renal expression of ICAM-1 in patients with kidney disease. Clin Nephrol 1997;48:85-91.

27 Mrowka C, Heintz B, Sieberth HG: VCAM-1, ICAM-1, and E-selectin in IgA nephropathy and Schönlein-Henoch syndrome: Differences between tissue expression and serum concentration. Nephron 1999;81:256-263.

28 Lai KN, Wong KC, Li PK, Lai CK, Chan CH, Lui SF, Chui YL, Haskard DO: Circulating leucocyte-endothelial adhesion molecules in $\operatorname{IgA}$ nephropathy. Nephron 1994;68:294-300.
29 Eddy AA: Experimental insights into the tubulointerstitial disease accompanying primary glomerular lesions. J Am Soc Nephrol 1994;5: 1273-1287.

30 Nikolic-Paterson DJ, Lan Hy, Atkins RC: Macrophages; in Nielson EG, Couser WG (eds): Immunologic Renal Diseases. Philadelphia, Lippincott-Raven, 1997, pp 567-586.

31 Ootaka T, Saito T, Soma J, Yusa A, Abe K: Mechanism of infiltration and activation of glomerular monocytes/macrophages in IgA nephropathy. Am J Nephrol 1997;17:137-145.

32 Yoshioka K, Takemura $\mathrm{T}$, Murakami K, Okada M, Yagi K, Miyazato H, Matsushima K, Maki S: In situ expression of cytokines in IgA nephritis. Kidney Int 1993;44:825-833.

33 Kashem A, Endoh M, Yano N, Yamauchi F, Nomoto Y, Sakai H, Kurokawa K: Glomerular $\mathrm{Fc} \alpha \mathrm{R}$ expression and disease activity in IgA nephropathy. Am J Kidney Dis 1997;30:389_ 396.

34 Katafuchi R, Oh Y, Hori K, Komota T, Yanase T, Ikeda K, Omura T, Fujimi S: An important role of glomerular segmental lesions on progression of IgA nephropathy: A multivariate analysis. Clin Nephrol 1994;41:191-198.

35 Packham DK, Yan HD, Hewitson TD, Nicholls KM, Fairley KE, Kincaid-Smith P, Becker GJ: The significance of focal sclerosis (FSHS) and nephrotic range proteinuria in IgA nephropathy. Clin Nephrol 1996;46:225-229.

36 Díaz-Gallo C, Kelley VR: Self-regulation of autoreactive kidney-infiltrating $\mathrm{T}$ cells in MRLlpr nephritis. Kidney Int 1993;44:692-699.

37 Schulz H, Karau A, Filsinger S, Schoels M, Kabelitz D, Richter R, Hansch GM: Tubular epithelial cells as accessory cells for superantigen-induced $\mathrm{T}$ cell activation. Exp Nephrol 1998;6:67-73.

38 Bohle A, Strutz F, Müller GA: On the pathogenesis of chronic renal failure in primary glomerulonephrities: A view from the interstitium. Exp Nephrol 1994;2:205-210.

39 Ootaka T, Saito T, Soma J, Sato H, Abe K: Glomerulointerstitial interaction of adhesion molecules in IgA nephropathy and membranoproliferative glomerulonephritis. Am J Kidney Dis 1997;29:843-850.

40 Chaudry PR, Wu B, King G, Campbell M, MacLeod AM, Haites EN, Simpson JG, Power DA: Adhesion molecule interactions in human glomerulonephritis: Importance of the tubulointerstitium. Kidney Int 1996;49:127-134.

41 Eddy AA: Role of cellular infiltrates in response to proteinuria. Am J Kidney Dis 2001; 37(1 suppl 2):25-29.

42 Johnson JP, Shaw S: N14 cluster report: CD54; in Knapp W, Dörken B, Rieber EP (eds): Leucocyte Typing IV. Oxford, Oxford University Press, 1989, pp 681-683, 1088. 